\title{
Learning-by-Teaching Without Audience Presence or Interaction: When and Why Does it Work?
}

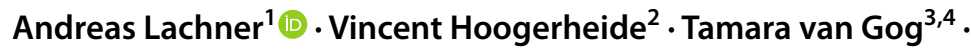 \\ Alexander Renkl ${ }^{5}$
}

Accepted: 19 October 2021 / Published online: 3 November 2021

(c) The Author(s) 2021, corrected publication 2022

\begin{abstract}
Teaching the contents of study materials by providing explanations to fellow students can be a beneficial instructional activity. A learning-by-teaching effect can also occur when students provide explanations to a real, remote, or even fictitious audience that cannot be interacted with. It is unclear, however, which underlying mechanisms drive learning by non-interactive teaching effects and why several recent studies did not replicate this effect. This literature review aims to shed light on when and why learning by non-interactive teaching works. First, we review the empirical literature to comment on the different mechanisms that have been proposed to explain why learning by non-interactive teaching may be effective. Second, we discuss the available evidence regarding potential boundary conditions of the non-interactive teaching effect. We then synthesize the available empirical evidence on processes and boundary conditions to provide a preliminary theoretical model of when and why non-interactive teaching is effective. Finally, based on our model of learning by non-interactive teaching, we outline several promising directions for future research and recommendations for educational practice.
\end{abstract}

Keywords Learning by teaching · Learning by explaining - Generative learning . Teaching on video

Andreas Lachner and Vincent Hoogerheide contributed equally to this work.

Andreas Lachner

andreas.lachner@uni-tuebingen.de

$\bowtie$ Vincent Hoogerheide v.hoogerheide@uu.nl

Extended author information available on the last page of the article 


\section{Introduction}

Seminal research documented that learning-by-teaching, that is explaining the contents of study materials to others, can be a beneficial instructional activity that improves the understanding of the person who teaches (Chi et al., 2001; Duran \& Topping, 2017; Plötzner et al., 1999; Roscoe \& Chi, 2008; Webb et al., 1995; see Duran, 2017 for an overview). Most studies investigating learning-by-teaching, entailed seeing and interacting with an audience (of one or more other people; Bargh \& Schul, 1980; Cohen et al., 1982). Recently, however, the effectiveness of learning-by-teaching has also been demonstrated without actual audience presence (i.e., teaching to fictitious or imagined fellow student(s); e.g., Fiorella \& Mayer, 2013; Hoogerheide et al., 2014). We will refer to this activity as learning by non-interactive teaching. Learning by non-interactive teaching is relevant for educational practice, as it can be realized as an individual study activity (e.g., during homework) that does not necessitate the presence of or interaction with a teacher or a fellow student. Although the empirical evidence for the effectiveness of non-interactive teaching scenarios has increased in recent years (see Table 1), it is still largely unclear which underlying mechanisms drive the non-interactive teaching effect. Moreover, some studies showed null-effects or even found detrimental effects of non-interactive teaching on (certain measures of) students' learning (e.g., Fiorella et al., 2017; Hoogerheide et al., 2016a; Lachner et al., 2021; Roscoe \& Chi, 2008). These mixed findings are likely a result of different study characteristics, which may indicate that there are boundary conditions that determine whether non-interactive teaching is effective or not.

Against this background, this literature review aims to shed light on when and why learning by non-interactive teaching works. We explicitly decided against a meta-analytical review in favor of a theoretical literature review, as our main aim was not to test the effectiveness of learning by non-interactive teaching (see Kobayashi, 2019; Lachner et al., 2021, for recent meta-analytical evidence). Rather, we aim to provide a theoretical model on the underlying cognitive and motivational processes of non-interactive teaching as well as to detail potential boundary conditions that might constrain the effectiveness of non-interactive teaching.

To provide a considerable database for our theoretical review, we searched for English empirical articles in the Google Scholar and the Web of Science data bases with the following search terms ("learning by teaching" | "learningby-teaching") and ("fictitious" | "non-present"). The use of these search terms was preceded by an initial screening phase, in which we examined whether the search terms were used in seminal articles on non-interactive teaching (Alexander, 2020). Articles were included if they (a) comprised an intervention in which learning by non-interactive teaching (e.g., teaching a fictitious or non-present person, providing an instructional explanation to a non-present person) was implemented, (b) followed an experimental research design (quasi-experimental, experimental), and (c) was published in a peer-reviewed academic journal.

We decided not to include literature on teachable agents, as despite some similarities, there are several important differences between (research on) the act of 


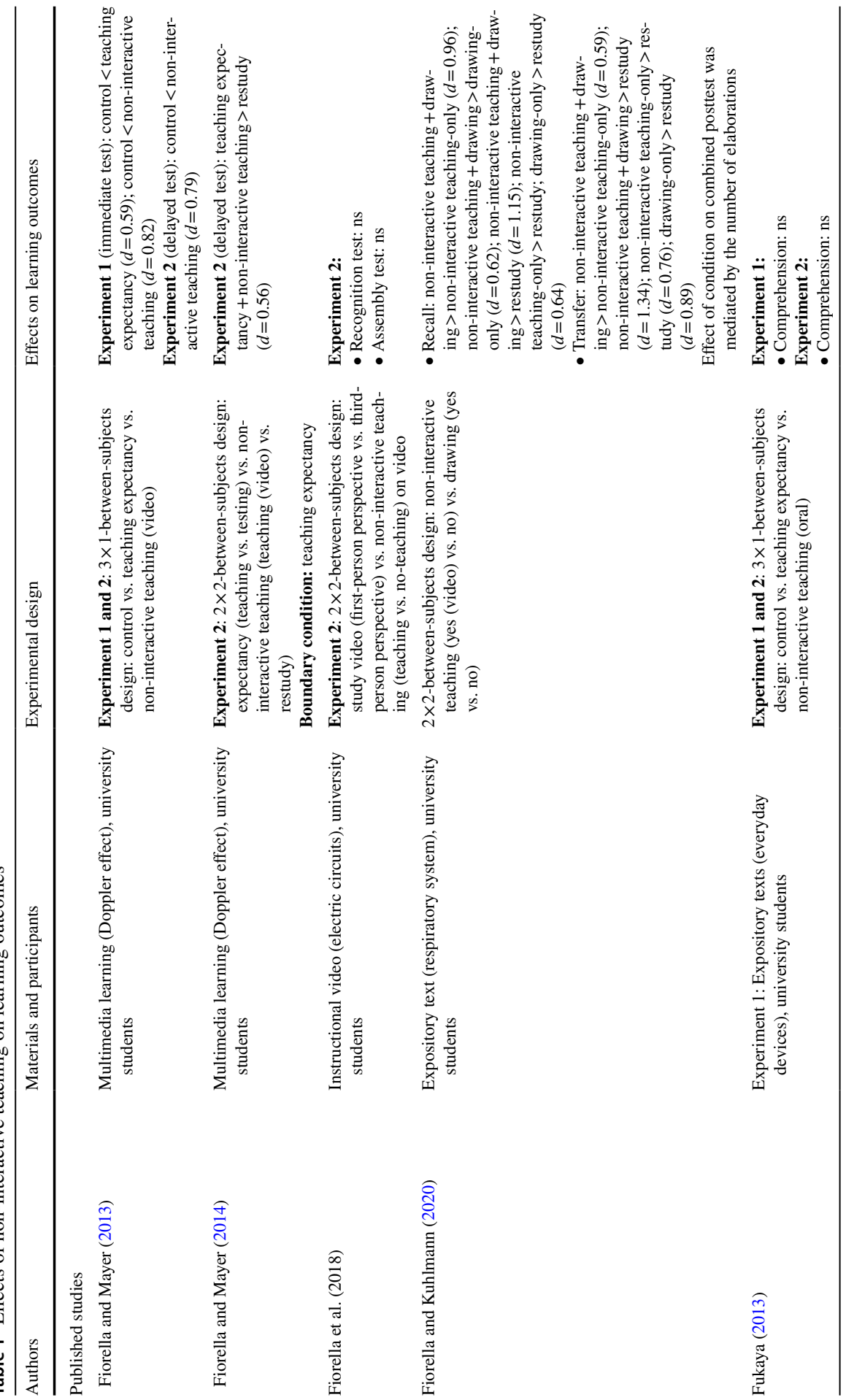




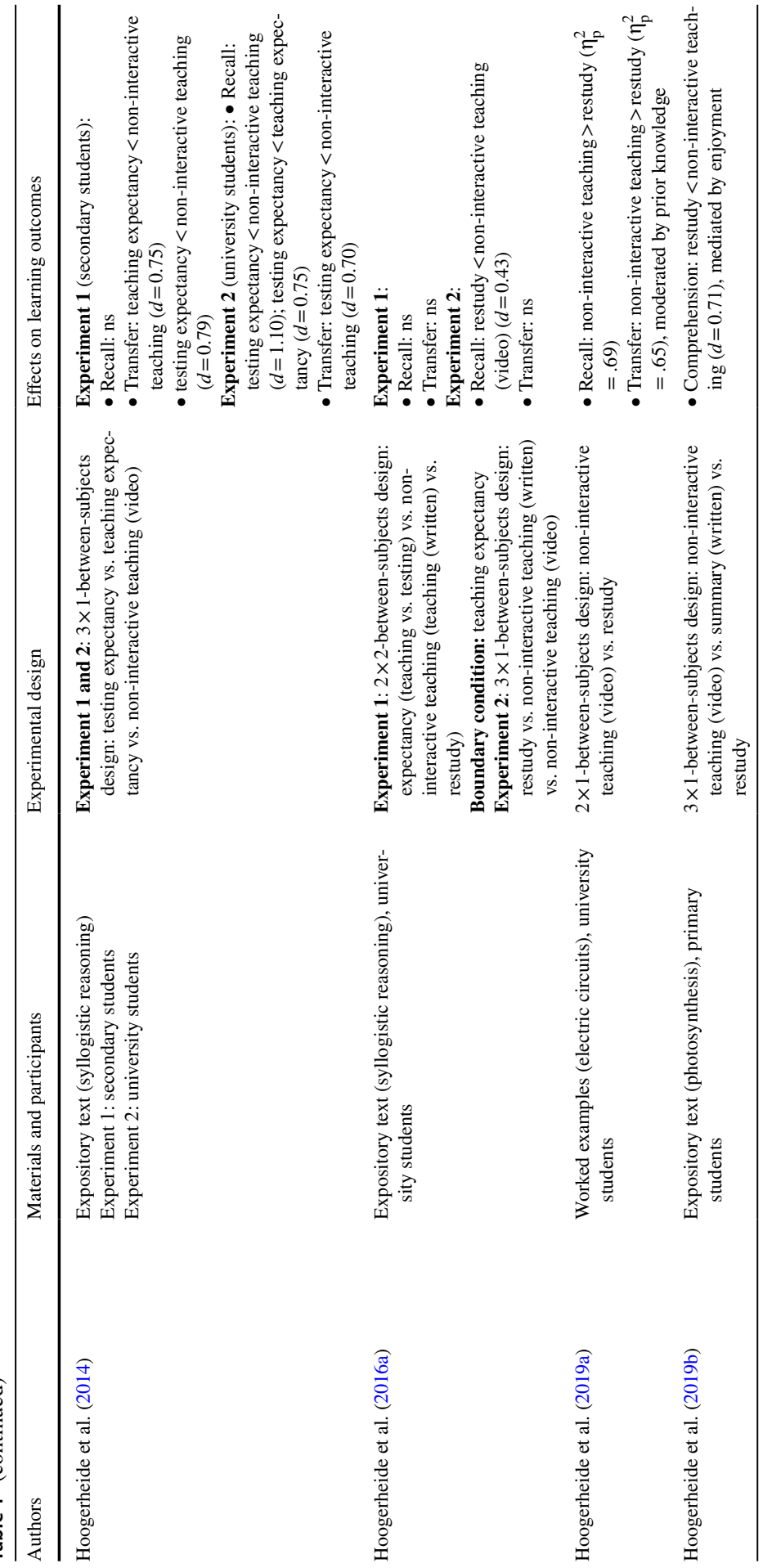




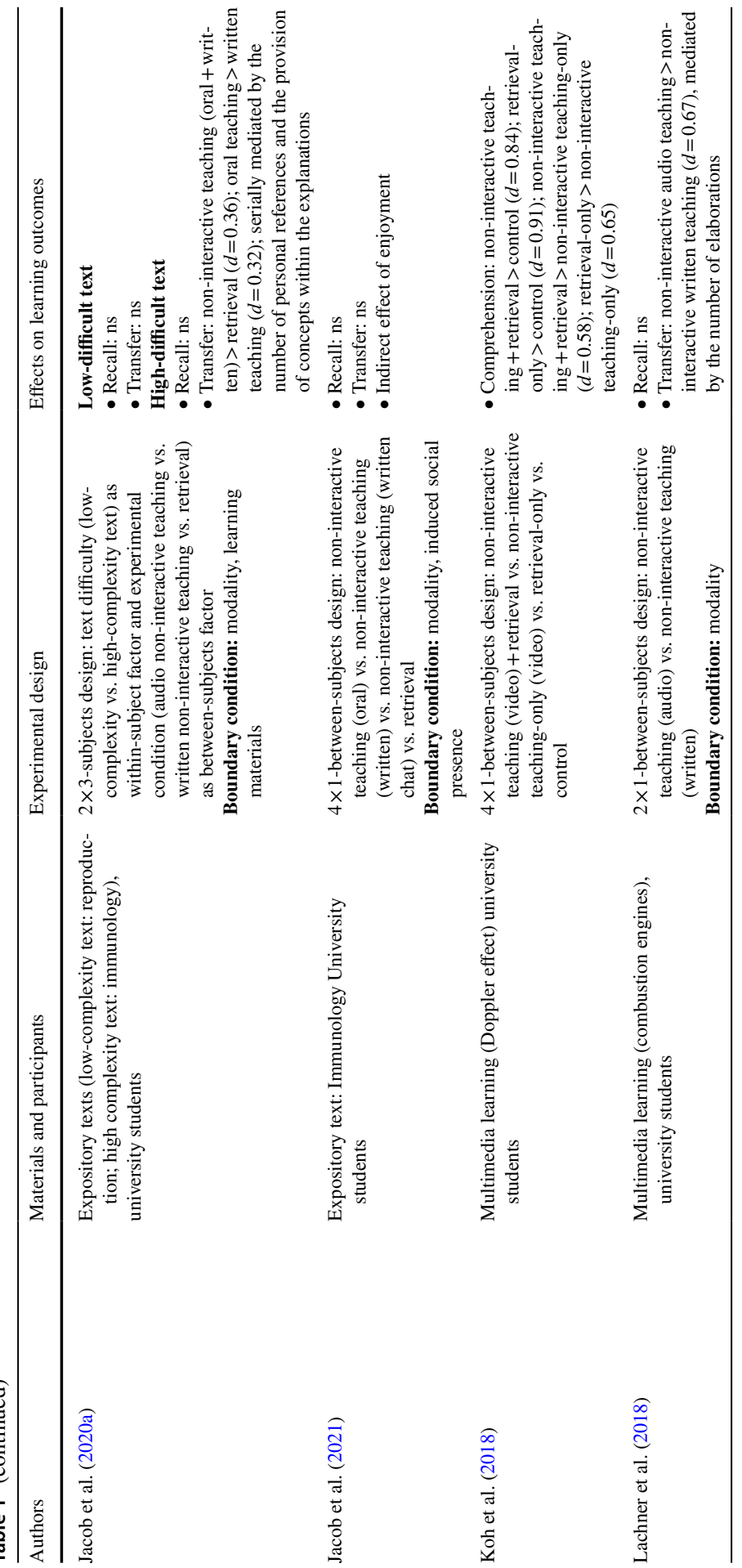




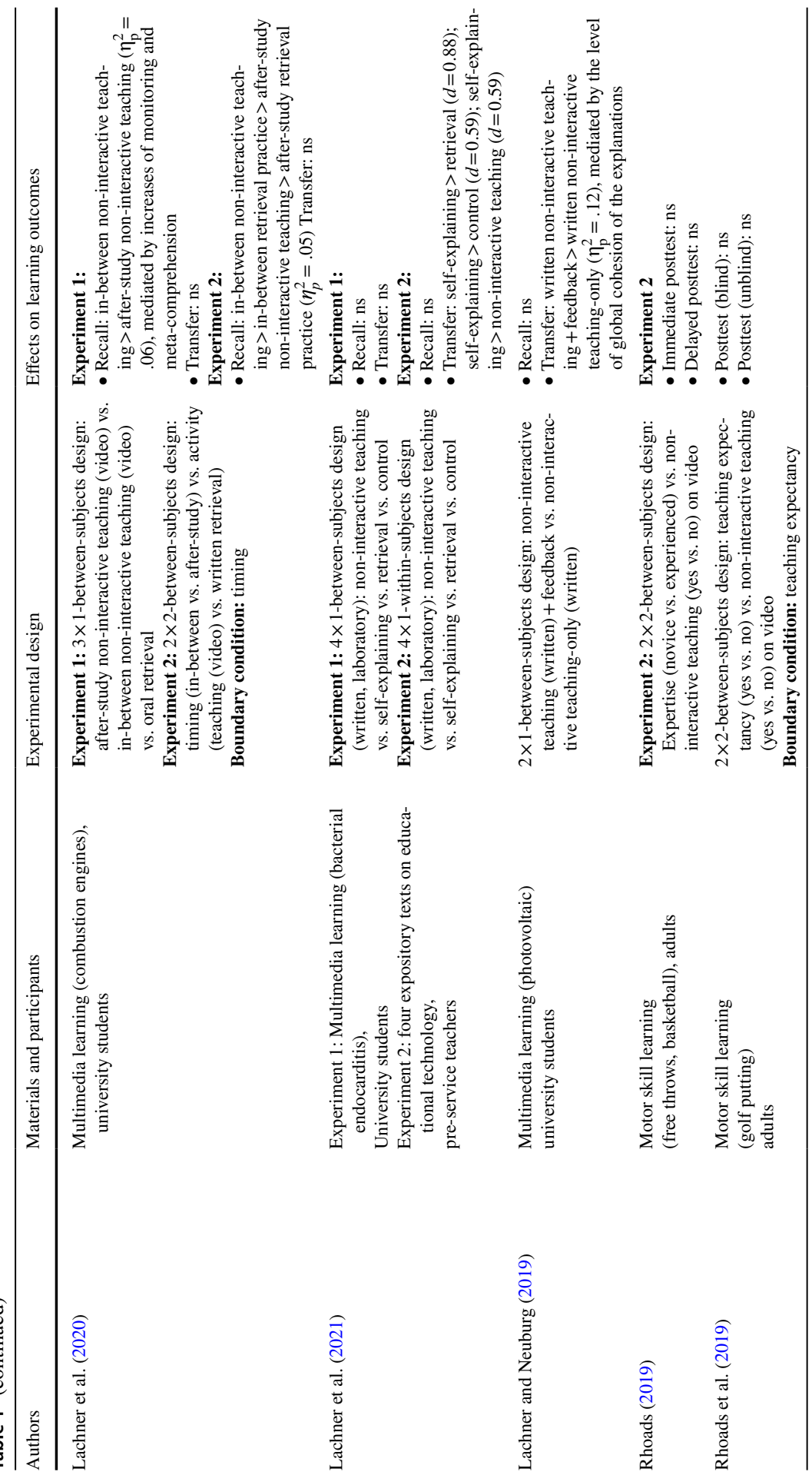




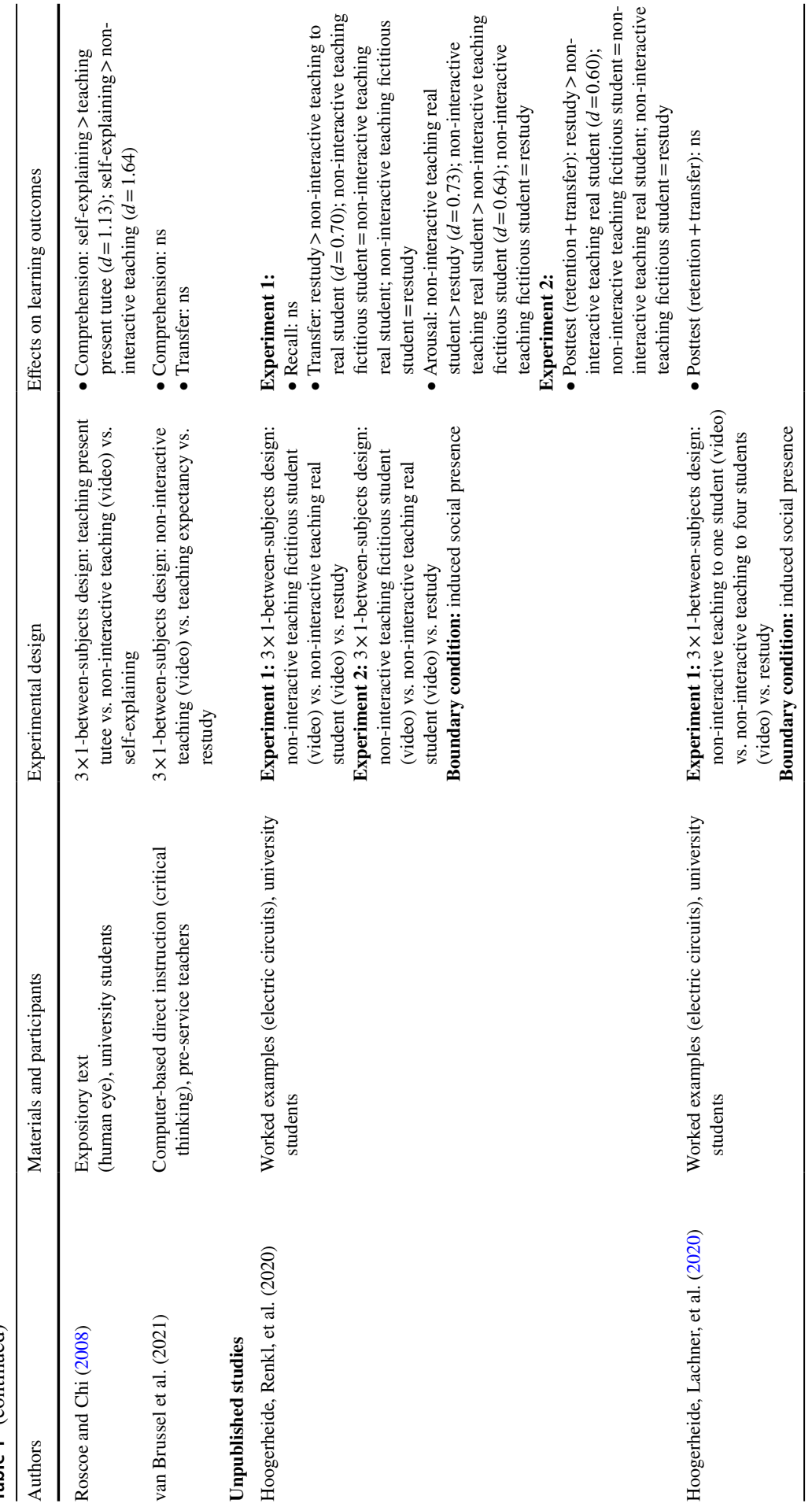




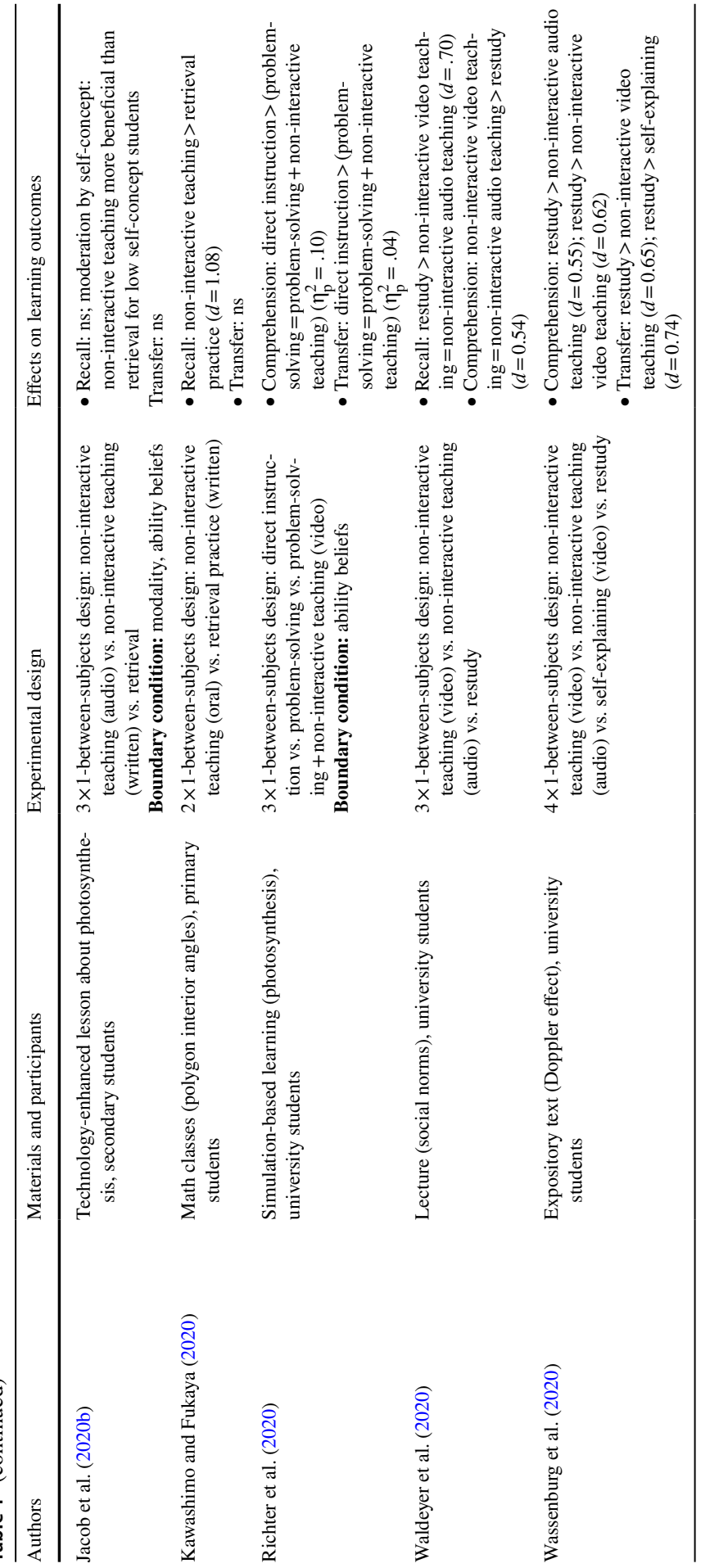


teaching a teachable agent and non-interactive teaching that make it difficult to compare the two. For example, in teachable agent studies, students typically do not realize natural discourse; instead, they tend to engage in very specific activities, such as completing graphical representations or answering multiple choice questions (e.g., Chin et al., 2010; Matsuda et al., 2013; Silvervarg et al., 2021). Another difference is that students who teach an agent typically receive quite some support, for instance in the form of adaptive metacognitive scaffolds or explicit feedback (e.g., Roscoe et al., 2013; Silvervarg et al., 2021; Tan et al., 2006). These differences make it difficult to compare these teaching situations to non-interactive teaching, where students engage in natural discourse and do not receive any support. Moreover, our inclusion criteria excluded almost all research on learning by generating a student product (e.g., websites, texts, videos for YouTube)—with the exception of Hoogerheide et al., (2019b) - because this body of research tends not have an experimental design (i.e., no control condition; e.g., Orús et al., 2016), not include a teaching component (e.g., research on learning by making summaries for someone else; Fiorella \& Mayer, 2016), and/or to allow students to generate the product in collaboration with other students which means there was an interaction component (e.g., Zahn et al., 2012, 2014).

The data search resulted in 236 hits (21 March 2020), from which 15 articles could be included, as they were thematically adequate (non-interactive teaching, experimental study), no duplicates, and primary English articles. Additionally, as recommended by Alexander (2020), we scanned the publication lists of prominent scholars (i.e., referential backtracking) who published journal articles about learning by non-interactive teaching for additional, relevant empirical work, which resulted in four additional articles. As a final safeguard, we also asked those scholars directly for potential gray literature (e.g., pre-prints) to provide an up-to-date overview of the current research literature on learning by non-interactive teaching. During the review process, we updated the literature with two articles on March 6, 2021. The entire procedure resulted in an inclusion of $n=25$ articles (see Table 1 for an overview).

Based on the available literature, we first provide an overview of the central assumptions of why non-interactive teaching is assumed to promote students' learning. Second, we review what potential boundary conditions may constrain the effectiveness of non-interactive teaching. We then synthesize the available empirical evidence on processes and boundary conditions to provide a preliminary theoretical model of when and why non-interactive teaching is effective. Finally, we outline fruitful avenues for future empirical research and provide recommendations for educational practice.

\section{What is Learning by (Non-Interactive) Teaching?}

Learning-by-teaching involves situations in which students explain the previously learnt contents to another student to stimulate generative cognitive processes that may be conducive to learning. Seminal research on this learning-by-teaching activity primarily focused on teaching in interactive settings, such as during peer tutoring 
or cooperative learning in classrooms or synchronous online learning environments (e.g., Annis, 1983; Bargh \& Schul, 1980; Cohen et al., 1982). In interactive settings, learning-by-teaching is commonly characterized by three (recurring) core processes: studying learning materials in preparation for teaching, explaining the content of the learning materials to other students, and discussing the materials with other students (Bargh \& Schul, 1980; Fiorella \& Mayer, 2016; Renkl, 1995). The preparation phase and the interaction between the teaching students and their fellow students are both believed to make a valuable contribution to the effectiveness of learning-by-teaching (e.g., Duran, 2017; Kobayashi, 2021). For instance, studying learning materials with the explicit expectation of teaching the content later on has been shown to enhance learning outcomes relative to studying for a test (e.g., Fiorella \& Mayer, 2013, 2014; see also section boundary conditions of non-interactive teaching). Additionally, during the interactions, for example, the fellow student may stimulate the teaching student's knowledge-building by pointing out inconsistencies, asking questions, and giving their own explanations (Plötzner et al., 1999; van der Veen et al., 2017; Webb et al., 1995).

However, recent research has shown that the learning-by-teaching effect also replicates in non-interactive settings (e.g., Fiorella \& Mayer, 2013; Hoogerheide et al., 2014; Pi et al., 2021; Rittle-Johnson et al., 2008). Learning by non-interactive teaching entails studying learning materials and then teaching the material to an actual, remote, or imaginary audience, and lacks interaction with other students. Learning by non-interactive teaching can therefore be considered as providing a "monologous instructional explanation" (see Chi et al., 2017). This activity has become common practice for students across different age groups (Orús et al., 2016; Pimmer et al., 2019). Due to technological developments such as widespread internet access and access to recording devices (e.g., mobile phones, tablets) as well as easy-to-use communication platforms (e.g., Explain Everything, WhatsApp, YouTube, TikTok), many students nowadays not only watch but also record messages demonstrating their knowledge or skills in both educational and informal settings.

When used as an instructional activity, students are often explicitly told to adopt a teaching role by communicating distinct information on the subject matter to a fictitious fellow student with low levels of prior knowledge (e.g., Hoogerheide et al., 2014; Lachner et al., 2020). These explanations are typically oral explanations and recorded, although there are also non-interactive teaching studies in which students had to provide written explanations (e.g., Hoogerheide et al., 2016a; Jacob et al., 2020b; Lachner et al., 2021). An example of the specific instructions students commonly receive is provided by Fiorella and Mayer (2014):

"You will study a short lesson on how the Doppler Effect works and then be asked to teach the material that you learned. Specifically, you will be expected to provide a short (up to 5 minutes) video-recorded lecture explaining how the Doppler Effect works as if you were teaching the material to someone who has no prior knowledge of the subject." (p. 80).

This example illustrates why non-interactive teaching is distinctly different from providing self-explanations, which entails instructing students to explain the subject matter to themselves (e.g., Bisra et al., 2018; Renkl \& Eitel, 2019; Roy \& Chi, 
2005). That is, although explaining is key to both non-interactive teaching and selfexplaining, self-explaining lacks the teaching component of instructing someone else. Moreover, there are other differences: For instance, self-explaining is often a concurrent activity during studying that is prompted to ensure high quality-explanations (e.g., Bisra et al., 2018; Fiorella et al., 2020; Rittle-Johnson \& Loehr, 2017; Roscoe \& Chi, 2008), whereas non-interactive teaching often happens after a full study phase and is not accompanied by additional instructional interventions such as prompts (see Bargh \& Schul, 1980; Lachner et al., 2020).

\section{Which Processes are Responsible for the Effectiveness of Learning by Non-Interactive Teaching?}

There are three (not mutually exclusive) main views that aim to explain the beneficial effects of learning by non-interactive teaching: (1) retrieval practice, (2) generative processing, and (3) social presence (of an actual/implied/imagined audience). First, the retrieval practice view suggests that non-interactive teaching simply functions as a special case of retrieval practice, as a considerable amount of teaching time is dedicated to actively retrieving the information about the previously studied material from memory (Koh et al., 2018). Memory research has repeatedly shown that accessing information from long-term memory can strengthen the activated memory cues with a variety of learning materials, such as wordlists and complex conceptual materials (Carpenter, 2009; Roediger \& Karpicke, 2006; Rowland, 2014). As such, explaining would mainly fulfill a consolidation function (see Waldeyer et al., 2020). Furthermore, research demonstrated that retrieval practice also supports students by helping them construct new retrieval cues (e.g., Carpenter, 2009; Endres \& Renkl, 2015; Endres et al., 2017; Roediger \& Butler, 2011; Rowland, 2014). From a cognitive perspective, retrieving information from memory supports the construction of new retrieval cues, likely because it helps students to activate the original and possibly also related information, thereby creating stronger retrieval traces that can more easily be activated (cf. elaborative retrieval hypothesis, Carpenter, 2009; Endres et al., 2017).

Second, according to the generative processing view, non-interactive teaching has benefits beyond retrieval practice, as explaining additionally triggers students' inference-making processes and may contribute to higher levels of generative processing as compared to retrieval practice (Fiorella \& Mayer, 2016; Roscoe \& Chi, 2008; cf. also cognitive elaboration perspective as described by Slavin, 1995). As such, noninteractive teaching may help students to actively process and make sense of the to-be-learned information (Renkl, 1995; Rittle-Johnson et al., 2008; Roscoe \& Chi, 2008). Therefore, according to the generative view, students primarily learn from the cognitive and metacognitive learning processes that occur during the reconstruction of information. Cognitive processes that occur during generative activities, such as organization and elaboration processes, help students build a coherent mental representation of the subject-matter and integrate the new information with existing prior knowledge (Fiorella \& Mayer, 2016; Kiewra, 2005; Wittrock, 1974). Metacognitive processes triggered by generative activities help students to evaluate their current 
understanding and to apply adequate regulation strategies to repair gaps in understanding (Fiorella \& Mayer, 2016; Lachner et al., 2020). Given that students rarely engage in such generative processes spontaneously (see Berthold \& Renkl, 2010; Nückles et al., 2020, for an overview), asking students to provide an explanation of the learning contents during non-interactive teaching may be conceived as a generative strategy activator (see Fiorella \& Mayer, 2016; Nückles et al., 2009; Reigeluth, 1983), which requires students to monitor their understanding due to an additional externalization of their knowledge, and subsequently re-organize and elaborate the contents in their explanations (Fiorella \& Mayer, 2016; Lachner et al., 2018; Roscoe \& Chi, 2008).

Third, a relatively novel perspective that has gotten distinct attention in recent research is the social presence view (Hoogerheide et al., 2016a, 2019a, b; Jacob et al., 2020a, 2021; Lachner et al., 2021). Social presence was originally defined as the extent to which people are aware of others in a technology-mediated setting and view those others as real (Short et al., 1976). More recently, following technological advances, this definition was updated to "the psychological phenomenon in which, to a certain extent, the other persons are perceived as physical 'real' persons in technology-mediated communication enabled by computer-mediated communication tools and electronic platforms" (Kreijns et al., 2021). The social presence view provides an extension of the generative processing view by arguing that the extent to which students engage in generative processing depends on the actual, implied, or imagined audience during teaching. Social presence effects are explained from three different perspectives. From a discourse pragmatics perspective (Lachner et al., 2021), it is assumed that students who engage in non-interactive teaching have a communication partner in mind to whom they direct their explanations during noninteractive teaching (Schober \& Brennan, 2003), which might trigger distinct adaption processes (Clark \& Brennan, 1991). For instance, students have to anticipate what the audience knows to adapt their teaching (Nickerson, 1999). These anticipation processes may trigger specific audience-adjustments (cf. audience design; Rogers et al., 2013), and for instance lead students generate additional elaborations during their teaching to make the content more comprehensible for less-knowledgeable learners (see Wittwer et al., 2010, for empirical evidence). As such, non-interactive teaching is commonly assumed to contribute even more to students' learning than ego-centric generative activities such as self-explaining.

The affective perspective proposes a second pathway that feelings of social presence also affect learning non-consciously via physiological arousal, which is a state of excitement or activation that causes an increase in heart rate, sweating, and blood pressure. It is well-established that both a real and an implied/imagined audience can elicit arousal and that the quality of task performance depends on people's physiological arousal levels, with a moderate degree of arousal being conducive to task performance compared to low and high levels of arousal (Aiello \& Douthitt, 2001; Bond \& Titus, 1983; Yerkes \& Dodson, 1908). Regarding the effect arousal has on complex learning, there is research showing that relative to low and high levels of arousal, a moderate arousal level enhances various determinants of learning, such as memory consolidation, attention, and working memory capacity (Arnsten, 2009; Sharot \& Phelps, 2004). Note that as a consequence, according to the affective 
perspective, the relationship between social presence and learning is not so straightforward and might follow a reversed $U$-shaped curve.

Relatedly, from a motivational perspective (Hoogerheide et al., 2019b), non-interactive teaching might be a relatively engaging and enjoyable way to learn, because it is an active study approach that stimulates feelings of social connectedness with the (imagined/implied) audience (cf. relatedness, Deci \& Ryan, 2012). As a result, learners might be motivated to do well and therefore invest more time and effort into learning relative to other study strategies that are more passive or do not have this audience component.

\section{Evidence for and Against the Retrieval, Generative, and Social Presence View of Non-Interactive Teaching}

To date, there is some empirical evidence for each view, but it is hard to gauge which of these three different accounts of the effects of non-interactive teaching is most likely valid, because most research did not explicitly or systematically test these different assumptions (see Table 1 for an overview). For instance, Koh et al. (2018) recently argued in favor of the retrieval view. In a lab experiment, Koh and colleagues compared the effects of non-interactive teaching to retrieval practice. After studying a multimedia lesson, students provided a video explanation without teaching notes (non-interactive-teaching-with-retrieval), recalled the information in written form (retrieval-only), or performed a filler task unrelated to the learning materials (control group). Another group of students additionally received a worked-out teaching script and was required to provide an explanation by reading the teaching script verbatim (non-interactive-teaching-without-retrieval). The authors found that students in the non-interactive-teaching-with-retrieval and the retrieval-only condition outperformed those who explained without retrieval and those in the control condition. However, there were no significant test performance differences between the non-interactive-teaching-with-retrieval and retrieval-only condition. Koh et al. (2018) interpreted the non-significant differences between the explaining and the retrieval condition in favor of the retrieval view. However, an important caveat of this study is that the non-interactive-teaching-without-retrieval condition simply read the teaching script aloud, which involved few if any generative or retrieval processes and might have led to a decrease in feelings of social presence. As such, the direct comparison between the retrieval and the non-retrieval condition has to be interpreted very cautiously.

Other recent studies showed initial evidence against the retrieval view and in favor of the generative view (see Table 1). For instance, Jacob et al. (2020a) and Lachner et al., (2020, Experiment 2) found that non-interactive teaching was more effective than a recall activity (see also Hoogerheide et al., 2014, Experiment 2; Hoogerheide et al., 2016a, Experiment 2). That said, in another study, Hoogerheide, Renkl, and colleagues (2019) found a teaching effect when students had access to the learning materials, which likely reduced the amount of active retrieval during noninteractive teaching. Further evidence in terms of the generative view comes from experimental studies which explicitly analyzed the characteristics that accounted 
for the students' learning, suggesting that particularly generative activities, such as making elaborations mediated the effect of non-interactive teaching on students' learning (e.g., Fiorella \& Kuhlmann, 2020; Lachner et al., 2018). Relatedly, several other studies found that non-interactive teaching improved students' monitoring accuracy (Fukaya, 2013; Jacob et al., 2020a), suggesting that non-interactive teaching not only fostered students' cognitive processing but also their metacognitive activities, as compared to retrieval practice. These findings suggest that, at the very least, the beneficial effects of non-interactive teaching cannot only be explained by the mere retrieval of information, although being able to successfully retrieve during teaching might be partly responsible for the non-interactive teaching effect (see Karpicke, 2017, for related evidence in the domain of retrieval practice). Relatedly, it must be noted that a large proportion of the studies only applied an immediate test, while retrieval activities might be most beneficial to learning after a delay (Fiorella \& Mayer, 2016; Rowland, 2014). However, those studies that did include a delayed test demonstrated beneficial effects of non-interactive teaching both on an immediate posttest and a delayed posttest with similar effect sizes across both test moments (e.g., Fiorella \& Mayer, 2014; Hoogerheide et al., 2014). Hence, it seems unlikely that test moment would be a boundary condition.

Referring to the discourse pragmatics perspective of social presence, Roscoe and Chi (2008) compared non-interactive teaching to interactive teaching (tutoring a peer which was present) and self-explaining, and as such varied the level of social presence, and associated anticipation processes. Surprisingly, the authors found that non-interactive teaching was less effective for learning than self-explaining or direct teaching. Analysis of the underlying cognitive and metacognitive processes during explaining revealed that self-explaining enhanced learning compared to non-interactive teaching because the self-explainers engaged more in knowledge-building processes and monitoring processes. Note that these results have to be interpreted with caution, because there were multiple differences between the non-interactive teaching and self-explaining condition that could have affected how much students learned. For instance, while the students who engaged in direct or non-interactive teaching provided their explanations after the study phase, the self-explainers were encouraged to continuously self-explain the content of the material while studying. These timing differences between conditions could have affected the findings (see Lachner et al., 2020).

Nevertheless, Lachner et al. (2021) found similar results while controlling for these potential confounding factors. They compared non-interactive teaching in written form (i.e., writing an explanation of the material to a fictitious peer) to writing self-explanations, and additionally included a written retrieval condition and a control condition (no study-relevant activity) as baseline. In a field-experiment, the self-explaining condition outperformed non-interactive teaching, retrieval, and the baseline condition. However, the authors did not replicate these results in a controlled laboratory setting. Neither self-explaining nor non-interactive teaching was more effective than retrieval or the control condition. The ineffectiveness of noninteractive teaching was possibly a result of the sample of students not having sufficient prior knowledge to benefit from non-interactive teaching (see also Wassenburg et al., 2020, Experiment 2, for related evidence on oral explaining). 
Regarding the affective perspective of social presence, Hoogerheide and colleagues examined the role of arousal (Hoogerheide et al., 2019a, 2020a, b). Across three experiments, the authors could show that non-interactive teaching was associated with measures of physiological arousal by means of electro-dermal activity. Arousal did not account for students' learning outcomes in any of the experiments.

Finally, there is some initial evidence for a motivational social presence effect. In a field experiment by Hoogerheide et al., (2019a, 2019b), primary education students studied a text over the weekend and subsequently engaged in generating a summary for themselves (generative activity, no social component), creating a non-interactive teaching video (generative activity, social component), or restudying (control; no generative activity, no social component). After the weekend, children completed questionnaires and a knowledge test. The findings showed that non-interactive teaching improved test performance compared to restudy, while summarizing was not more effective than restudy. Moreover, teaching was more enjoyable than both summarizing and restudying, which mediated the effect of non-interactive teaching on test performance (see Jacob et al., 2021, for similar evidence in a controlled laboratory setting). One has to be cautious with interpreting these findings, however, as an alternative explanation for both the motivational and learning benefits of creating a non-interactive teaching video is that this was a more novel activity for the children than summarizing or restudying. The novelty effect proposes that when technologies are new, performance improves because the situational interest in the technology stimulates effort investment and persistence, yet performance quickly declines again as situational interest disappears (Clark, 1983).

In summary, the available empirical evidence suggests that non-interactive teaching is more than just a specific case of retrieval practice. There is evidence for a link between generative processing and learning as well as between social presence and learning (see Table 1). However, to which degree these two factors drive the (in-)effectiveness of non-interactive teaching is unclear. Most experiments were not designed to explicitly test the generative and social presence view, but rather investigated whether non-interactive teaching promotes learning or not relative to other common instructional strategies. The experiments that did explicitly test the underlying mechanisms by experimentally manipulating degrees of social presence during teaching (e.g., Hoogerheide et al., 2020b; Lachner et al., 2021) suggested that social presence during non-interactive teaching may be regarded as a double-edged sword, as high levels of social presence impaired rather than contributed to learning. There is some evidence to suggest that the motivational component of social presence accounted for the effectiveness of learning by non-interactive teaching, as increases of motivation could explain potential effects of non-interactive teaching (Hoogerheide et al., 2019b; Jacob et al., 2021).

\section{Potential Boundary Conditions of Non-Interactive Teaching}

Below, we provide an overview of potential boundary conditions of non-interactive teaching. Most of the studies on non-interactive teaching did not explicitly test for boundary conditions of non-interactive teaching. As such, the available evidence on 
potential boundary conditions at the time of writing the theoretical review should be considered to be preliminary.

\section{Modality: Spoken Versus Written Non-Interactive Teaching}

Recent findings indicate that the modality of the non-interactive teaching activity matters. For example, Hoogerheide et al., (2016a) had students teach a fictitious fellow student aloud (on camera) or in writing. The content that they studied and taught was syllogistic reasoning. The authors found no direct differences between oral and written non-interactive teaching. However, whereas oral non-interactive teaching was more effective than restudy (see Table 1), written non-interactive teaching did not improve learning outcomes compared to restudy. In a related study with more complex materials (i.e., texts about combustion engines), Lachner et al. (2018) even found that oral non-interactive teaching enhanced learning more than written teaching (see also Jacob et al., 2020a).

These findings could be explained from a cognitive load perspective, as writing explanations may be more cognitively demanding and more time-consuming, because writing is a less automated process compared to speaking (see Cleland \& Pickering, 2006; Sperling, 1996). However, with the exception of Hoogerheide et al., (2016a), none of the studies revealed differences between written and oral non-interactive teaching on measures of subjective cognitive load (Jacob et al., 2020a, 2021; Lachner et al., 2018). In line with the social presence view, social presence is discussed as an alternative theoretical account for why modality matters, as writing may trigger lower levels of social presence than speaking (Hoogerheide et al., 2016a; Jacob et al., 2020a). In several studies, it was found that students in the writing condition used fewer personal references (i.e., first and second personal pronouns) in their explanations than those in the oral condition, while there were no differences between the two teaching conditions regarding perceived difficulty or invested mental effort (see Hoogerheide et al., 2016a; Jacob et al., 2020a; Lachner et al., 2018). Personal references are commonly regarded as a coarse proxy of social presence in discourse pragmatics (see also Akinnaso, 1985; Chafe, 1982). Initial evidence suggested such a pathway via social presence, as Jacob et al. (2020a) documented that the effects of modality on learning outcomes could be explained by differences in personal references and the number of elaborated concepts. However, more validity studies which triangulate different methods are needed to clarify whether such a coarse proxy can be used to measure social presence, given that the relation between perceptions of social presence and the use of personal references is not fully clear (see Jacob et al., 2021, for mixed findings).

As an aside, a related issue is that researchers have used different types of recording of oral non-interactive explanations: audio (e.g., Jacob et al., 2020a; Lachner et al., 2018) or video (e.g., Fiorella \& Mayer, 2013; Hoogerheide et al., 2019a, b; Lachner et al., 2020). Being aware that the non-verbal communication component is captured on video could increase perceptions of social presence (see Yoo \& Alivi, 2001). However, the two studies that directly manipulated whether students provided 
audio or video (oral) explanations showed no effects on learning outcomes (Waldeyer et al., 2020; Wassenburg et al., 2020).

\section{Induced Social Presence by the Teaching Task}

Another potential boundary condition is the level of perceived social presence induced by the teaching task. In line with the Yerkes-Dodson law (Yerkes \& Dodson, 1908), the available evidence suggests that when the instruction of the teaching task affords high levels of social presence, non-interactive teaching loses its benefits and can even impair learning. Hoogerheide, Renkl, and colleagues (2020) foundacross two separate experiments - that teaching the content of an example to another remote person via a webcam (a confederate who only listened; high social presence) impaired performance on an immediate and delayed problem-solving posttest relative to studying that example (no social presence), while teaching an example to a fictitious person (moderate social presence) did not impair (or improve) problemsolving performance relative to the study control condition. Explaining the example to a real person was particularly detrimental to performance on transfer tasks, suggesting that (too) high levels of social presence can impair students' understanding of the material. A recent study of Hoogerheide, Lachner, et al. (2020) also suggests that a high level of social presence is detrimental to the quality of students' cognitive schemata: Non-interactive teaching an example on video to four people (higher social presence) was as effective but a lot less efficient (i.e., resulted in similar test performance attained with a lot more mental effort) relative to explaining to one person (lower social presence). Note, however, that despite the fact that these experiments manipulated the core components of the social presence construct (i.e., degree of awareness/realness of audience), none of these experiments had an explicit measure of social presence, so there was no manipulation check, which warrants caution. Another study by Jacob et al. (2021) aimed at manipulating social presence through the teaching task-rather than the audience-by asking students to explain via a messenger chat including additional social cues, such as the recipients profile picture and a query message by the potential recipient (higher social presence) or to explain via a text editor without any social cues. The authors found that students in the messenger condition included more personal references, as potential behavioral proxy for social presence. These higher levels of social presence in the messenger condition, however, did not affect test performance relative to explaining in a text editor.

\section{Timing of the Study Tasks}

One study task-related boundary condition is the sequencing of the study and teaching tasks. Most research followed a study-teaching-test sequence in which students first studied the learning materials, taught the content of the study phase, and finally completed a posttest (e.g., Fiorella \& Mayer, 2014; Fukaya, 2013; Hoogerheide et al., 2014, 2019a, b; Rhoads et al., 2019). The preference for teaching being the final task of the learning phase stems from the generative view, as non-interactive 
teaching after a full study phase is believed to trigger students to create inferences about and elaborate on the contents, which should in turn result in deeper learning (Bargh \& Schul, 1980; Renkl, 1995). Yet, there are reasons to believe that noninteractive teaching earlier in the learning phase (e.g., between study phases) is even more beneficial for learning than teaching late. Explaining early in the study phase could trigger students' metacognitive monitoring of their understanding, and help them become aware of potential knowledge deficits, which they can then try to resolve during further studying - provided that there is another study phase.

Across two experiments, Lachner et al. (2020) tested this assumption in the context of non-interactive teaching by having students teach between two study phases, in which they read two different passages of an expository text on combustion engines, or at the end, after reading both texts. A third group recalled the learning contents at the end of the study phase. The findings demonstrated no overall effect of teaching in comparison to retrieval. However, teaching between the study phase contributed to students' comprehension more than teaching after the study phase. Analyses of the generated explanations showed that the effect of early explaining was mediated by an increase in students' metacognitive monitoring.

\section{Teaching Expectancy}

A key question is whether or not studying with the expectancy of having to teach the learning materials to another person (without actually teaching) would already improve students' learning and help them make the most out of a later teaching activity (Fiorella \& Mayer, 2016). Although this issue received quite some attention in non-interactive teaching research (e.g., Fiorella \& Mayer, 2013; Hoogerheide et al., 2014) and in the early interactive teaching literature (e.g., Benware \& Deci, 1984; Renkl, 1995; Ross \& Di Vesta, 1976), research has yielded mixed findings. Several studies found that studying learning materials with a teaching expectancy improved learning outcomes relative to studying for a test (e.g., Fiorella \& Mayer, 2013; Nestojko et al., 2014), while others found no differences (e.g., Hoogerheide et al., 2016a; Rhoads et al., 2019).

More importantly, there is some evidence that studying with a teaching expectancy can moderate the effectiveness of non-interactive teaching. Fiorella and Mayer (2014) allocated university students to one of four conditions following a 2 (study with test vs. teaching expectancy) $\times 2$ (non-interactive teaching vs. restudy) design. The authors found a moderation effect of teaching expectancy on learning by teaching: Students who made a video lesson performed better on a delayed comprehension test than those who restudied, and this non-interactive teaching effect was largest when preceded by a teaching expectancy than by a test expectancy. This moderation effect, however, could often not be replicated in other studies (e.g., Hoogerheide et al., 2014, 2016a; Rhoads et al., 2019; Wang et al., 2021), which is likely a result of the fact that the teaching expectancy effect is rather small (see Kobayashi, 2019) and that most studies did not have a large enough sample for reliably testing small (interaction) effects. 


\section{Inter-individual Effects of Prior Knowledge}

Prior knowledge is a key moderating factor in research on learning and instruction (e.g., Kalyuga et al., 2003), and it is likely that students' knowledge prior to the teaching activity would also moderate the effect of non-interactive teaching on learning outcomes. As stated before, it is common for researchers to use a study-teaching-test sequence, presumably because teaching after a full study phase means that students have enough prior knowledge to generate high-quality explanations. The idea to maximize prior knowledge at the point of teaching is also in line with research on retrieval practice, as retrieval practice opportunities are most effective, if learners are able to successfully retrieve enough information of the learning materials (see Rowland, 2014). By contrast, students who have hardly any prior knowledge obviously cannot benefit from non-interactive teaching, as they would have little to explain.

The only empirical evidence on the importance of prior knowledge is provided by Hoogerheide et al., (2019a). They found that teaching the content of an example on how to troubleshoot electrical circuits improved problem-solving performance on retention (i.e., isomorphic) and transfer problems relative to studying that example. The effect on transfer was moderated by students' prior conceptual knowledge: Students who initially had low knowledge of the conceptual information required to understand the problemsolving task (e.g., the relationships among resistance, current, and voltage) profited more from non-interactive teaching than studying, while those with higher prior conceptual knowledge performed comparable regardless of experimental condition. It is possible that teaching helped students with lower conceptual knowledge to elaborate on the material and generate inferences, while this was not necessary for those who already had higher conceptual knowledge. These findings have to be interpreted with caution, however, as it is unclear what level of conceptual/procedural knowledge students had exactly prior to teaching (i.e., in-between the pretest and teaching, students were provided with two examples and a practice problem). Moreover, this moderation effect could not be replicated in other studies (e.g., Jacob et al., 2020b).

By contrast, there is also evidence that learners with too little conceptual prior knowledge do not benefit much from non-interactive teaching, as recent studies with rather lowprior knowledge learners found that non-interactive teaching was comparably or even less effective relative to simple learning strategies such as restudying the learning materials or free recall (Lachner et al., 2020, Experiment 1; Lachner et al., 2021; Wassenburg et al., 2020). The likely explanation is that in these studies, students did not have sufficient knowledge that would allow for the generation of elaborations and inferences during teaching.

\section{Inter-individual Effects of Students' Ability Beliefs}

Although non-interactive teaching research has predominantly focused on cognitive aspects of learning (i.e., learning outcomes and mental effort investment), there are reasons to believe that students' beliefs about their own abilities might be another critical boundary condition of instructional interventions (see Roelle \& Renkl, 2020). Such ability beliefs are based on past experiences (e.g., self-concept, Marsh, 1990) and anticipated future experiences (e.g., self-efficacy, Bandura, 1989) and have been shown to be closely related to 
learning gains (e.g., Caprara et al., 2008; Wäschle et al., 2014). A likely reason is that students with high ability beliefs have been shown to realize more deep-learning strategies. Apparently, students with high ability beliefs are more aware of their learning capabilities and therefore show greater persistence during learning activities, which eventually contributes to their achievement in a cyclical and reciprocal manner (Roelle \& Renkl, 2020; Wäschle et al., 2014). In contrast, students with low ability beliefs may require additional help to initiate deep-learning strategies, such as by means of non-interactive teaching.

Investigating effects of academic self-concept, which is sometimes referred to as ability beliefs of past experiences, Jacob et al. (2020b) found that the non-interactive teaching effect was moderated by students' domain-specific self-concept. After a learning unit on photosynthesis, students were either engaged in non-interactive teaching (written/ oral) or in restudy. The authors did not obtain a main effect of non-interactive teaching. However, additional moderation analyses revealed an interaction of self-concept and non-interactive teaching. Students with low levels of self-concept profited from noninteractive teaching as compared to restudy, while those with high self-concept did not. The authors attributed their findings to differences in perception of the social audience: Students with low self-concept profited more from non-interactive teaching, because it may have triggered a social situation of productive knowledge exchange, as both the audience and the "teacher" had comparable prerequisites. This perception might induce a situation of information sharing (see Ray et al., 2013), as both the producer and the recipient have high similarities (see Hoogerheide, van Wermeskerken, et al., 2016). Students with high self-concept, however, may no longer benefit from non-interactive teaching because they perceive to teach to a less capable peer. Such a situation may create a social situation implying downward comparisons, which have been shown to yield lower levels of information sharing (Ray et al., 2013), and likely lower learning gains. These interpretations, however, would have to be tested by future experimental research.

\section{Characteristics of Learning Materials}

Finally, the effectiveness of non-interactive teaching may depend on characteristics of the learning materials. For instance, there is initial evidence that the complexity of the learning materials matters. Jacob et al. (2020a) varied the linguistic complexity of texts and asked students to learn two texts, one of low complexity and one of high complexity, in a within-subjects design. Afterwards, students either retrieved or taught the contents of the texts. While teaching was more beneficial than retrieval for the high-complexity text, there were no differences among conditions with the low-complexity text. Low-complexity material in combination with tasks that require to retrieve the previously learnt contents might already sufficiently support students in constructing a coherent representation of the text (Berendes et al., 2018; McNamara, 2013), and make subsequent generative activities, such as non-interactive teaching obsolete. In contrast, highcomplexity materials may require adding teaching activities to support students establish a coherent understanding of the text (see also Roelle \& Nückles, 2019).

Next to material complexity, the nature of the materials might play a role. Noninteractive teaching research has mostly used conceptual materials (e.g., Fiorella \& 
Mayer, 2013, 2014; Hoogerheide et al., 2014). Recent studies examined whether the teaching effect would replicate with procedural materials, such as electronic troubleshooting tasks or inquiry tasks (Fiorella et al., 2017; Hoogerheide et al., 2019a, 2020a, b; Richter et al., 2020) or motor learning (Rhoads, 2019; Rhoads et al., 2019). Surprisingly, all these studies showed null effects, with the exception of Hoogerheide et al., (2019a), who found that teaching the content of an example improved problem-solving performance relative to studying that example. This effect, however, was qualified by an interaction with prior knowledge, as only low-prior knowledge students profited from teaching. In the same vein, three additional experiments with the same materials and similar student populations could not replicate this effect (Hoogerheide et al., 2020a, b). These findings may suggest that non-interactive teaching is not a beneficial instructional activity for procedural learning. However, we want to note that procedural learning tasks such as learning problem-solving skills from examples often also require considerable understanding about the underlying concepts (see Rittle-Johnson \& Alibali, 1999), suggesting that the null findings found with procedural tasks were perhaps qualified by the type of problem-solving posttest test rather than the type of learning material.

A possible explanation for why non-interactive teaching may be particularly conducive to conceptual learning and less so to procedural learning, is that the cognitive processes stimulated by non-interactive teaching are better aligned with the processes required for conceptual learning than procedural learning. The aim of conceptual learning is to build up a rich conceptual network by acquiring distinct concepts as well as by relating these concepts to each other and to previously acquired conceptual information (i.e., prior knowledge) (Anderson, 1985; de Jong \& Ferguson-Hessler, 1996). As learning by teaching entices students to explain potential why-questions of a fictitious peer, it allows for the generation of inferences and elaborations and could thereby help students integrate new concepts to their prior conceptual knowledge, and organize these concepts into a coherent representation (Fiorella et al., 2020; Lachner et al., 2018). Inferences and elaborations might not be as useful for procedural learning, because procedural learning requires students to acquire distinct rules and productions which are continuously automated and stored in procedural memory (e.g., Anderson, 1985). Self-explaining may have a similar function as non-interactive teaching regarding the support of conceptual understanding. However, in contrast to non-interactive teaching, self-explaining tasks are often accompanied by specific instructions to elicit the desired self-explanation processes (e.g., by comparing different examples and explaining the underlying rationale; see Rittle-Johnson \& Loehr, 2017).

\section{A Preliminary Model of Learning by Non-Interactive Teaching and Directions for Future Research}

A synthesis of the available evidence on the underlying processes and the boundary conditions of learning by non-interactive teaching can be found in Fig. 1. Our model postulates that how much students learn from non-interactive teaching depends on 
the design of the teaching task (i.e., task level), what students do/feel during the teaching task (i.e., process level), and who the students are (i.e., student level).

In the center, the synthesized model highlights the processes that are considered pivotal in determining the effectiveness of learning by non-interactive teaching. There is considerable evidence that students' learning depends on the extent to which they engage in cognitive processes such as generating elaborations and inferences as well as metacognitive processes such as comprehension monitoring (e.g., Fiorella \& Kuhlmann, 2020; Lachner et al., 2018). Note that we view retrieving information from memory as one of these key generative processes (cf. Koh et al., 2018). Moreover, there is evidence that there is an important role for (processes triggered by) perceptions of social presence, and that the effects of social presence are mediated by motivational processes (Hoogerheide et al., 2019b; Jacob et al., 2021) and adaptation processes (Jacob et al., 2020a; Lachner et al., 2018). Motivation and adaption are assumed to influence learning outcomes via an adjustment in (meta) cognitive processes. Note that we did not include the affective perspective on social presence, because presently there is no evidence for a link between arousal and performance.

The top square of the model details the five task-related boundary conditions that have been found to influence the effectiveness of non-interactive teaching. Although there is only "initial" evidence for two of these factors (i.e., studying with a teaching expectancy and complexity/type of materials), there is considerable evidence that the non-interactive teaching task should not induce high levels of social presence, yet should instruct students to teach earlier on in the learning phase (rather than only at the end), and to speak the explanations aloud (rather than in written form). The bottom part of the model depicts potential effects of student-related boundary conditions. So far, there is initial evidence for the role of students' ability beliefs

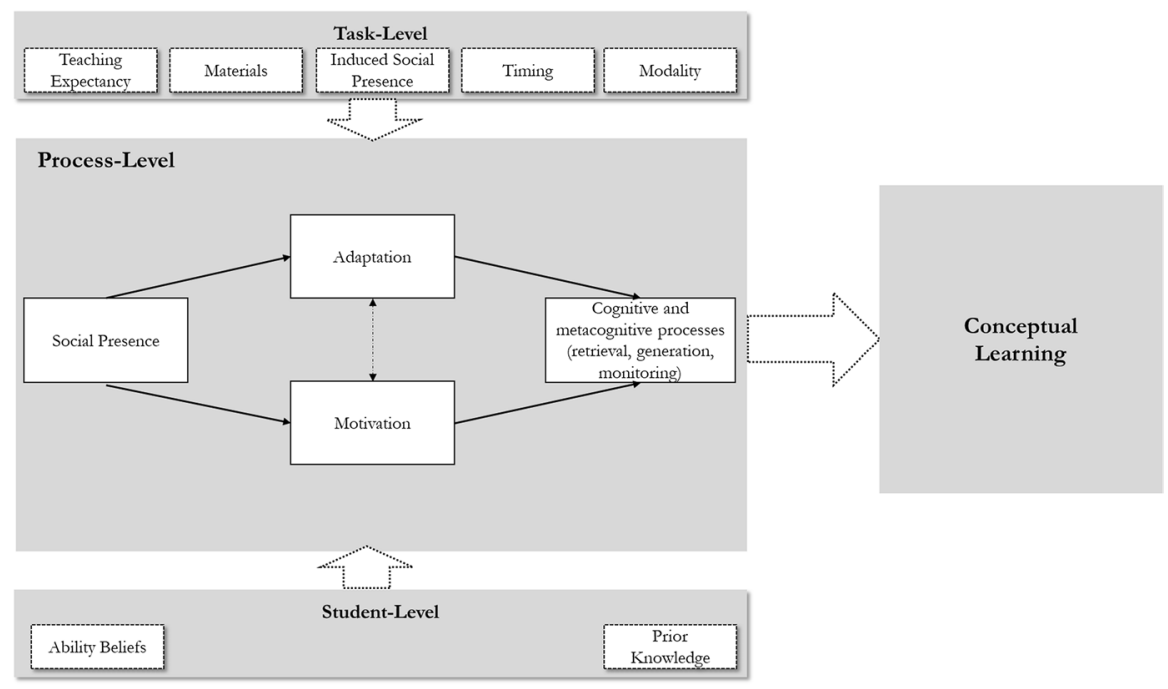

Fig. 1 A preliminary model of learning by non-interactive teaching 
(i.e., academic self-concept; Jacob et al., 2020b) and prior knowledge (Hoogerheide et al., 2019a). However, because these effects were only found in one study, they clearly require replication, ideally in studies which experimentally vary these interindividual factors.

The literature reviewed in this article revealed important insights into when and why non-interactive teaching is conducive for learning. At the same time, as indicated by the preliminary model, our review identified crucial blind spots of this research field that open up important potential avenues for further research.

\section{Research Agenda 1: Mechanisms of Non-Interactive Teaching}

Our literature review highlighted the need to conduct more research explicitly targeted towards uncovering the potential mechanisms responsible for the effects of learning by non-interactive teaching, as most of the studies were not designed to test and compare the different mechanisms. Hence, we would argue that future research should experimentally disentangle the potential effects of retrieval, generation, and perceptions of social presence. A fruitful approach for instance could be to cross different factors such as the availability of learning materials (open- versus closedbook) to manipulate the amount of retrieval activities during non-interactive teaching (see Hiller et al., 2020, for related approaches on self-explaining), and the social presence during the teaching tasks, for instance by manipulating the presence of a student (e.g., Hoogerheide et al., 2020b; Lachner et al., 2021).

Any such examinations should preferably include (multiple) process measures. Recent studies did start to include process measures, such as arousal (Hoogerheide et al., 2019a; Pi et al., 2021), motivation (Hoogerheide, et al., 2019b; Jacob et al., 2021), or adaption processes (Fiorella \& Kuhlmann, 2020; Jacob et al., 2020a; Lachner et al., 2020). However, most studies only included a single process measure, making it difficult to compare the relative relevance and the interplay of different mechanisms. Relatedly, only two studies attempted to measure perceptions of social presence (Jacob et al., 2021; van Brussel et al., 2020). Therefore, a potential goal for future research could be to triangulate these measures to provide integrated answers to which mechanisms account for the effects of learning by non-interactive teaching and how these mechanisms relate to one another.

\section{Research Agenda 2: Individual Differences in the Effectiveness of Non-Interactive Teaching}

Our review and model highlight that there is a paucity of research examining the potential importance of individual differences, with the exception of ability beliefs and prior knowledge, which received some attention but require replication to be considered as robust moderators. Hence, we stress the importance of uncovering other potential characteristics that could determine the effectiveness of non-interactive teaching.

For instance, following research on teacher expertise (Borko \& Livingston, 1989; Lachner et al., 2016; Leinhardt \& Greeno, 1986), teaching experience could be such a 
moderating factor (see Herppich et al., 2014, for empirical evidence in the context of tutoring). Teaching experience could cause students to have more accurate beliefs about what constitutes effective explanations during teaching, to be better at monitoring whether explanations are comprehensible for the audience, and to experience fewer negative emotions during teaching (e.g., worrying thoughts) which might allow more working memory resources to be dedicated to the activity of teaching. Relatedly, from a motivational perspective, the role of teaching efficacy may deserve further attention, as the beliefs about one's own competence to realize distinct teaching tasks have been shown to considerably affect the quality of teaching (see Klassen \& Tze, 2014, for an overview). From a methodological perspective, in addition to moderation analyses, an alternative approach would be to experimentally manipulate these characteristics (see Fyfe \& Rittle-Johnson, 2016; Wolff et al., 2018, for empirical examples). Such approaches would allow for drawing causal conclusions regarding the effects of student-related boundary conditions.

\section{Research Agenda 3: Enhancing the Effectiveness of Non-Interactive Teaching}

Related to the issue of uncovering for which learners and when non-interactive teaching works best, we want to emphasize the need of investigating how to further enhance the effectiveness of non-interactive teaching. This question is crucial for educational practitioners who (want to) utilize this strategy in practice. One fruitful way might be to examine how to best sequence non-interactive teaching in relation to or in combination with other effective instructional activities, because the effects of non-interactive teaching were mainly examined "in isolation" (for an exception, see Fiorella \& Kuhlmann, 2020). Based on the moderating role of prior knowledge, it seems sensible to expect that learning by teaching is particularly suited for advanced (i.e., later) phases of knowledge acquisition, to enable students to provide high-quality explanations (see Lachner et al., 2021, for related discussions). Other generative strategies such as drawing that directly support the construction of knowledge (rather than mainly have a consolidation function) might be more suited for earlier phases of knowledge acquisition (see also Fiorella \& Kuhlmann, 2020; Fiorella \& Mayer, 2016, for related discussions).

Another approach is to examine the effects of providing instructional support during the teaching activity. To date, only one study examined the effects of providing such support (Lachner \& Neuburg, 2019). In this study, the authors demonstrated that the addition of formative feedback during non-interactive teaching enhanced the quality of the generated explanation, which yielded deeper comprehension. Further inspiration could be drawn from the rich body of research on enhancing the effectiveness of self-explaining or writing interventions (Bisra et al., 2018; Klein et al., 2018). For instance, regarding self-explaining, it is well-documented that focused prompting (e.g., Johnson \& Mayer, 2010; Renkl \& Eitel, 2019; Rittle-Johnson \& Loehr, 2017) or even explicit training (e.g., Kurby et al., 2012) helps students make better self-explanations and thereby learn more. It seems sensible to assume that these strategies also work for non-interactive teaching. Additionally, research in the field of teacher education may provide further useful insights into how explaining skills can be enhanced (Findeisen et al., 2020; Weinhuber et al., 2019), for instance 
by video-based interventions to make non-interactive teaching more effective. Such interventions could not only comprise strategies of generating high-quality explanations, but also help students' monitoring whether their explanations are comprehensible for their audience.

\section{Research Agenda 4: Bringing Non-interactive Teaching Into the Wild}

A further caveat of previous research is that because most empirical studies were conducted in the laboratory (see Hoogerheide et al., 2019b; Jacob et al., 2020b; Lachner et al., 2021, for exceptions), it is largely unclear whether findings transfer to educational practice. It is possible that non-interactive teaching would become more effective in applied settings. All the studies included in our review used a "stripped down" version of non-interactive teaching by limiting which activities students could engage in and for how long. Often, students were given a limited amount of time to prepare their teaching, not allowed to take notes, or not informed at all before the study phase that they would have to teach the learning materials. Moreover, students were never allowed to revise their oral teaching scripts or to redo the teaching activity (see Lachner \& Neuburg, 2019, for exceptions on written teaching). It is likely that in applied settings when students are in control of their learning, they would make different choices (e.g., prepare longer, generate a teaching script, restudy parts of the learning materials, engage in repeated teaching), which could enhance how much they learn. Moreover, as many studies only included an immediate posttest (see Fiorella \& Mayer, 2014; Hoogerheide et al., 2014, for exceptions), future research should include more delayed measurements to examine whether any effects remain stable after a delay. Ideally, the effects of non-interactive teaching would be examined in an applied setting and over time, for instance as part of a multi-week course. Such designs would allow to test whether findings of non-interactive teaching may arouse by the activity itself or, for example, simply because of a kind of novelty effect (Clark, 1983).

A final limitation of the previous studies refers to the fact that most studies were conducted with learning materials from the STEM domain, which often rely heavily on visuo-spatial processing (e.g., Doppler effect, respiratory system, motor engine). As such, it is unclear whether the findings on learning by non-interactive teaching would replicate with learning materials from different domains (e.g., liberal arts). Similarly, the vast majority of studies used self-study materials (e.g., expository texts, multimedia material), so it is unclear whether the findings would hold in more complex learning scenarios such as actual teaching.

\section{Conclusions}

Despite the increased interest from researchers and practitioners in learning by noninteractive teaching in recent years, our knowledge of when and why non-interactive teaching promotes learning was still limited. In this review, we have taken a step 
toward filling this knowledge gap by reviewing the available literature on processes and potential boundary conditions of non-interactive teaching which we synthesized into a to-be-updated model. We hope that this review successfully delineated a research agenda that can help transition this relatively young but promising field of research from investigating whether non-interactive teaching is an effective instructional activity to why and under which conditions non-interactive teaching promotes learning and how its effectiveness could be further improved. Given that research on non-interactive teaching is relatively recent, a large proportion of included studies was gray literature (i.e., non-published studies), which at the time of writing this review had not been peer-reviewed yet. On the one hand, one may argue that there is a chance that these papers could be of a somewhat "lower quality" due to lower levels of quality control. On the other hand, including gray literature may also help reduce publication bias and increase the comprehensiveness and timeliness of the review.

We also hope that this review will help teachers who (want to) utilize non-interactive teaching in their classes or as homework assignments to ensure that their implementation of this activity is as effective as possible. Based on the limited available evidence, it seems advisable to use non-interactive teaching as an activity when students have to acquire complex conceptual knowledge from expository texts or multimedia material. It seems less useful when students have to acquire more basic conceptual knowledge or procedural knowledge (although it does not hurt learning in this case, the lack of significant gains should be weighed against the higher effort this activity requires from students). Moreover, it seems best to let students (1) explain aloud (rather than in writing), (2) explain from memory (rather than with the materials available to them), (3) study the materials with a teaching expectancy prior to the non-interactive teaching activity, and (4) restudy the materials again after teaching (rather than placing the non-interactive teaching activity at the end). However, given that research has mostly focused on the question of whether this activity works or not, more research is needed to determine under which conditions non-interactive teaching works best, and it is important that future research explicitly tests these boundary conditions.

Funding Open Access funding enabled and organized by Projekt DEAL.

Open Access This article is licensed under a Creative Commons Attribution 4.0 International License, which permits use, sharing, adaptation, distribution and reproduction in any medium or format, as long as you give appropriate credit to the original author(s) and the source, provide a link to the Creative Commons licence, and indicate if changes were made. The images or other third party material in this article are included in the article's Creative Commons licence, unless indicated otherwise in a credit line to the material. If material is not included in the article's Creative Commons licence and your intended use is not permitted by statutory regulation or exceeds the permitted use, you will need to obtain permission directly from the copyright holder. To view a copy of this licence, visit http://creativecommons.org/licen ses/by/4.0/. 


\section{References}

Aiello, J. R., \& Douthitt, E. A. (2001). Social facilitation from Triplett to electronic performance monitoring. Group Dynamics: Theory, Research, and Practice, 5, 163-180. https://doi.org/10.1037// 1089-2699.5.3.163

Akinnaso, F. N. (1985). On the similarities between spoken and written language. Language and Speech, 28(4), 323-359. https://doi.org/10.1177/002383098502800401

Alexander, P. A. (2020). Methodological guidance paper: The art and science of quality systematic reviews. Review of Educational Research, 90(1), 6-23. https://doi.org/10.3102/0034654319 854352

Anderson, J. R. (1985). A series of books in psychology. Cognitive psychology and its implications ( $2^{\text {nd }}$ ed.). W H Freeman/Times Books/ Henry Holt \& Co.

Annis, L. F. (1983). The processes and effects of peer tutoring. Human Learning: Journal of Practical Research \& Applications, 2(1), 39-47.

Arnsten, A. F. T. (2009). Stress signalling pathways that impair prefrontal cortex structure and function. Nature Reviews Neuroscience, 10, 410-422. https://doi.org/10.1038/nrn2648

Bandura, A. (1989). Regulation of cognitive processes through perceived self-efficacy. Developmental Psychology, 25(5), 729-735. https://doi.org/10.1037/0012-1649.25.5.729

Bargh, J. A., \& Schul, Y. (1980). On the cognitive benefits of teaching. Journal of Educational Psychology, 72(5), 593. https://doi.org/10.1037/0022-0663.72.5.593

Benware, C. A., \& Deci, E. L. (1984). Quality of learning with an active versus passive motivational set. American Educational Research Journal, 21(4), 755-765. https://doi.org/10.2307/1162999

Berendes, K., Vajjala, S., Meurers, D., Bryant, D., Wagner, W., Chinkina, M., \& Trautwein, U. (2018). Reading demands in secondary school: Does the linguistic complexity of textbooks increase with grade level and the academic orientation of the school track? Journal of Educational Psychology, 110(4), 518-543. https://doi.org/10.1037/edu0000225

Berthold, K., \& Renkl, A. (2010). How to foster active processing of explanations in instructional communication. Educational Psychology Review, 22(1), 25-40. https://doi.org/10.1007/ s10648-010-9124-9

Bisra, K., Liu, Q., Nesbit, J. C., Salimi, F., \& Winne, P. H. (2018). Inducing self-explanation: A meta-analysis. Educational Psychology Review, 30, 703-725. https://doi.org/10.1007/ s10648-018-9434-x

Bond, C. F., \& Titus, L. J. (1983). Social facilitation: A meta-analysis of 241 studies. Psychological Bulletin, 94, 264-292. https://doi.org/10.1037/0033-2909.94.2.265

Borko, H., \& Livingston, C. (1989). Cognition and improvisation: Differences in mathematics instruction by expert and novice teachers. American Educational Research Journal, 26(4), 473-498. https:// doi.org/10.3102/00028312026004473

Caprara, G. V., Fida, R., Vecchione, M., Del Bove, G., Vecchio, G. M., Barbaranelli, C., \& Bandura, A. (2008). Longitudinal analysis of the role of perceived self-efficacy for self-regulated learning in academic continuance and achievement. Journal of Educational Psychology, 100(3), 525-534. https://doi.org/10.1037/0022-0663.100.3.525

Carpenter, S. K. (2009). Cue strength as a moderator of the testing effect: The benefits of elaborative retrieval. Journal of Experimental Psychology: Learning, Memory, and Cognition, 35(6), 15631569. https://doi.org/10.1037/a0017021

Chafe, W. (1982). Integration and involvement in speaking, writing, and oral literature. In D. Tannen (Ed.), Spoken and written language: Exploring orality and literacy (pp. 35-53). Ablex.

Chi, M. T. H., Kang, S., \& Yaghmourian, D. L. (2017). Why students learn more from dialogue-than monologue-videos: Analyses of peer interactions. Journal of the Learning Sciences, 26(1), 10-50. https://doi.org/10.1080/10508406.2016.1204546

Chi, M. T. H., Siler, S. A., Jeong, H., Yamauchi, T., \& Hausmann, T. (2001). Learning from human tutoring. Cognitive Science, 25(4), 471-533. https://doi.org/10.1016/S0364-0213(01)00044-1

Chin, D. B., Dohmen, I. M., Cheng, B. H., Oppezzo, M. A., Chase, C. C., \& Schwartz, D. L. (2010). Preparing students for future learning with teachable agents. Educational Technology Research \& Development, 58(6), 649-669. https://doi.org/10.1007/s11423-010-9154-5

Clark, R. E. (1983). Reconsidering research on learning from media. Review of Educational Research, 53(4), 445-459. https://doi.org/10.3102/00346543053004445 
Clark, H. H., \& Brennan, S. E. (1991). Grounding in communication. In L. B. Resnick, J. M. Levine, \& S. D. Teasley (Eds.), Perspectives on socially shared cognition (p. 127-149). American Psychological Association. https://doi.org/10.1037/10096-006

Cleland, A. A., \& Pickering, M. J. (2006). Do writing and speaking employ the same syntactic representations? Journal of Memory and Language, 54(2), 185-198. https://doi.org/10.1016/j.jml.2005.10. 003

Cohen, P. A., Kulik, J. A., \& Kulik, C.-L.C. (1982). Education outcomes of tutoring: A meta-analysis of findings. American Educational Research Journal, 19(2), 237-248. https://doi.org/10.2307/11625 67

Deci, E. L., \& Ryan, R. M. (2012). Self-determination theory. In P. A. M. Van Lange, A. W. Kruglanski, \& E. T. Higgins (Eds.), Handbook of theories of social psychology (p. 416-436). Sage Publications Ltd. https://doi.org/10.4135/9781446249215.n21

de Jong, T., \& Ferguson-Hessler, M. G. M. (1996). Types and qualities of knowledge. Educational Psychologist, 31(2), 105-113. https://doi.org/10.1207/s15326985ep3102_2

Duran, D. (2017). Learning-by-teaching: Evidence and implications as a pedagogical mechanism. Innovations in Education and Teaching International, 54(5), 476-484. https://doi.org/10.1080/14703 297.2016.1156011

Duran, D., \& Topping, K. J. (2017). Learning by teaching: Evidence-based strategies to enhance learning in the classroom. London \& New York: Routledge.

Endres, T., Carpenter, S., Martin, A., \& Renkl, A. (2017). Enhancing learning by retrieval: Enriching free recall with elaborative prompting. Learning and Instruction, 49, 13-20. https://doi.org/10.1016/j. learninstruc.2016.11.010

Endres, T., \& Renkl, A. (2015). Mechanisms behind the testing effect: An empirical investigation of retrieval practice in meaningful learning. Frontiers in Psychology. https://doi.org/10.3389/fpsyg. 2015.01054

Findeisen S., Deutscher, V. K., \& Seifried, J. (2020). Fostering prospective teachers' explaining skills during university education-Evaluation of a training module. Higher Education, 1-17.

Fiorella, L., \& Kuhlmann, S. (2020). Creating drawings enhances learning by teaching. Journal of Educational Psychology, 112(4), 811-822. https://doi.org/10.1037/edu0000392

Fiorella, L., \& Mayer, R. E. (2013). The relative benefits of learning by teaching and teaching expectancy. Contemporary Educational Psychology, 38(4), 281-288. https://doi.org/10.1016/j.cedpsych.2013. 06.001

Fiorella, L., \& Mayer, R. E. (2014). Role of expectations and explanations in learning by teaching. Contemporary Educational Psychology, 39(2), 75-85. https://doi.org/10.1016/j.cedpsych.2014.01.001

Fiorella, L., \& Mayer, R. E. (2016). Eight ways to promote generative learning. Educational Psychology Review, 28(4), 717-741. https://doi.org/10.1007/s10648-015-9348-9

Fiorella, L., Stull, A. T., Kuhlmann, S., \& Mayer, R. E. (2020). Fostering generative learning from video lessons: Benefits of instructor-generated drawings and learner-generated explanations. Journal of Educational Psychology, 112(5), 895-906. https://doi.org/10.1037/edu0000408

Fiorella, L., van Gog, T., Hoogerheide, V., \& Mayer, R. E. (2017). It's all a matter of perspective: Viewing first-person video modeling examples promotes learning of an assembly task. Journal of Educational Psychology, 109(5), 653-665. https://doi.org/10.1037/edu0000161

Fukaya, T. (2013). Explanation generation, not explanation expectancy, improves metacomprehension accuracy. Metacognition and Learning, 8(1), 1-18. https://doi.org/10.1007/s11409-012-9093-0

Fyfe, E. R., \& Rittle-Johnson, B. (2016). Feedback both helps and hinders learning: The causal role of prior knowledge. Journal of Educational Psychology, 108(1), 82. https://doi.org/10.1037/edu00 00053

Herppich, S., Wittwer, J., Nückles, M., \& Renkl, A. (2014). Addressing knowledge deficits in tutoring and the role of teaching experience: Benefits for learning and summative assessment. Journal of Educational Psychology, 106(4), 934-945. https://doi.org/10.1037/a0036076

Hiller, S., Rumann, S., Berthold, K., \& Roelle, J. (2020). Example-based learning: Should learners receive closed-book or open-book self-explanation prompts? Instructional Science, 48, 623-649. https://doi.org/10.1007/s11251-020-09523-4

Hoogerheide, V., Deijkers, L., Loyens, S. M., Heijltjes, A., \& van Gog, T. (2016a). Gaining from explaining: Learning improves from explaining to fictitious others on video, not from writing to them. Contemporary Educational Psychology, 44, 95-106. https://doi.org/10.1016/j.cedpsych.2016.02. 005 
Hoogerheide, V., Lachner, A., Jacob, L., Glogger-Frey, I., van Gog, T., \& Renk1, A. (2020a). Does the effectiveness of learning by non-interactive teaching depend on the size of the audience?. Manuscript in preparation.

Hoogerheide, V., Loyens, S. M., \& van Gog, T. (2014). Effects of creating video-based modeling examples on learning and transfer. Learning and Instruction, 33, 108-119. https://doi.org/10.1016/j. learninstruc.2014.04.005

Hoogerheide, V., Renkl, A., Fiorella, L., Paas, F., \& van Gog, T. (2019a). Enhancing example-based learning: Teaching on video increases arousal and improves problem-solving performance. Journal of Educational Psychology, 111(1), 45-56. https://doi.org/10.1037/edu0000272

Hoogerheide, V., Renkl, A., Glogger-Frey, I., Lachner, A., Ravensbergen, S., \& van Gog, T. (2020b). Testing the social presence hypothesis: Teaching a real student impairs problem-solving performance. Manuscript in preparation.

Hoogerheide, V., van Wermeskerken, M., Loyens, S. M., \& van Gog, T. (2016b). Learning from video modeling examples: Content kept equal, adults are more effective models than peers. Learning and Instruction, 44, 22-30. https://doi.org/10.1016/j.learninstruc.2016.02.004

Hoogerheide, V., Visee, J., Lachner, A., \& van Gog, T. (2019b). Generating an instructional video as homework activity is both effective and enjoyable. Learning and Instruction, 64, 101226. https://doi.org/10.1016/j.learninstruc.2019.101226

Jacob, L., Lachner, A., \& Scheiter, K. (2021). Does increasing social presence enhance the effectiveness of writing explanations? PLOS ONE. https://doi.org/10.1371/journal.pone.0250406

Jacob, L., Lachner, A., \& Scheiter, K. (2020a). Learning by explaining orally or in written form? Text Difficulty Matters. Learning and Instruction, 68, 101344. https://doi.org/10.1016/j.learninstruc. 2020.101344

Jacob, L., Lachner, A., \& Scheiter, K. (2020b). Self-concept but not modality constrains the effectiveness of generating explanations. Manuscript submitted for publication.

Johnson, C. I., \& Mayer, R. E. (2010). Applying the self-explanation principle to multimedia learning in a computer-based game-like environment. Computers in Human Behavior, 26, 1246-1252. https://doi.org/10.1016/j.chb.2010.03.025

Kalyuga, S., Ayres, P., Chandler, P., \& Sweller, J. (2003). Expertise reversal effect. Educational Psychologist, 38, 23-31. https://doi.org/10.1207/S15326985EP3801_4

Karpicke, J. D. (2017). Retrieval-based learning: A decade of progress. In J. H. Byrne (Ed.), Learning and memory: A comprehensive reference (2nd ed., pp. 487-514). Academic Press.

Kawashimo, M., \& Fukaya, T. (2020). The effects of teaching-based reflection on pupils' mathematical understanding. Manuscript in preparation.

Kiewra, K. A. (2005). Learn how to study and SOAR to success. Pearson Prentice Hall.

Klassen, R. M., \& Tze, V. M. (2014). Teachers' self-efficacy, personality, and teaching effectiveness: A meta-analysis. Educational Research Review, 12, 59-76. https://doi.org/10.1016/j.edurev. 2014.06.001

Klein, P. D., Haug, K. N., \& Bildfell, A. (2018). Best practices in writing to learn. In S. Graham, C. A. MacArthur, \& M. Hebert (Eds.), Best practices in writing instruction ( $3^{\text {rd }}$ ed.; pp. 162-184). The Guilford Press.

Kobayashi, K. (2019). Learning by preparing-to-teach and teaching: A meta-analysis. Japanese Psychological Research, 61, 192-203. https://doi.org/10.1111/jpr.12221

Kobayashi, K. (2021). Learning by teaching face-to-face: The contributions of preparing-to-teach, initial-explanation, and interaction phases. European Journal of Psychology of Education. Advance online publication.

Koh, A. W. L., Lee, S. C., \& Lim, S. W. H. (2018). The learning benefits of teaching: A retrieval practice hypothesis. Applied Cognitive Psychology, 32(3), 401-410. https://doi.org/10.1002/ acp. 3410

Kreijns, K., Xu, K., \& Weidlich, J. (2021). Social presence: Conceptualization and measurement. Educational Psychology Review. https://doi.org/10.1007/s10648-021-09623-8

Kurby, C. A., Magliano, J. P., Dandotkar, S., Woehrle, J., Gilliam, S., \& McNamara, D. S. (2012). Changing how students process and comprehend texts with computer-based self-explanation training. Journal of Educational Computing Research, 4(4), 429-459. https://doi.org/10.2190/ EC.47.4.e

Lachner, A., Backfisch, I., Hoogerheide, V., van Gog, T., \& Renkl, A. (2020). Timing matters! Explaining between study phases enhances students' learning. Journal of Educational Psychology, 112(4), 841-853. https://doi.org/10.1037/edu0000396 
Lachner, A., Jacob, L., \& Hoogerheide, V. (2021). Learning by writing explanations: Is explaining to a fictitious student more effective than self-explaining? Learning and Instruction, 74, 101438. https://doi.org/10.1016/j.learninstruc.2020.101438

Lachner, A., Jarodzka, H., \& Nückles, M. (2016). What makes an expert teacher? Investigating teachers' professional vision and discourse abilities. Instructional Science, 44(3), 197-203. https://doi.org/ 10.1007/s11251-016-9376-y

Lachner, A., Ly, K.-T., \& Nückles, M. (2018). Providing written or oral explanations? Differential effects of the modality of explaining on students' conceptual learning and transfer. Journal of Experimental Education, 86(3), 344-361. https://doi.org/10.1080/00220973.2017.1363691

Lachner, A., \& Neuburg, C. (2019). Learning by writing explanations: Computer-based feedback about the explanatory cohesion enhances students' transfer. Instructional Science, 47(1), 19-37. https:// doi.org/10.1007/s11251-018-9470-4

Leinhardt, G., \& Greeno, J. G. (1986). The cognitive skill of teaching. Journal of Educational Psychology, 78(2), 75. https://doi.org/10.1037/0022-0663.78.2.75

Marsh, H. W. (1990). The structure of academic self-concept: The Marsh/Shavelson model. Journal of Educational Psychology, 82(4), 623-636. https://doi.org/10.1037/0022-0663.82.4.623

Matsuda, N., Yarzebinski, E., Keiser, V., Raizada, R., Cohen, W. W., Stylianides, G. J., \& Koedinger, K. R. (2013). Cognitive anatomy of tutor learning: Lessons learned with SimStudent. Journal of Educational Psychology, 18(3), 181-208. https://doi.org/10.1037/a0031955

McNamara, D. S. (2013). The epistemic stance between the author and reader: A driving force in the cohesion of text and writing. Discourse Studies, 15(5), 579-595. https://doi.org/10.1177/14614 45613501446

Nestojko, J. F., Bui, D. C., Kornell, N., \& Bjork, E. L. (2014). Expecting to teach enhances learning and organization of knowledge in free recall of text passages. Memory \& Cognition, 42(7), 1038-1048. https://doi.org/10.3758/s13421-014-0416-z

Nickerson, R. S. (1999). How we know—and sometimes misjudge-what others know: Imputing one's own knowledge to others. Psychological Bulletin, 125(6), 737-759. https://doi.org/10.1037/00332909.125.6.737

Nückles, M., Hübner, S., \& Renkl, A. (2009). Enhancing self-regulated learning by writing learning protocols. Learning and Instruction, 19(3), 259-271. https://doi.org/10.1016/j.learninstruc.2008.05. 002

Nückles, M., Roelle, J., Glogger-Frey, I., Waldeyer, J., \& Renkl, A. (2020). The self-regulation-view in writing-to-learn: Using journal writing to optimize cognitive load in self-regulated learning. Educational Psychology Review. Advance online publication. https://doi.org/10.1007/ s10648-020-09541-1

Orús, C., Barlés, M. J., Belanche, D., Casaló, L., Fraj, E., \& Gurrea, R. (2016). The effects of learnergenerated videos for YouTube on learning outcomes and satisfaction. Computers \& Education, 95 , 254-269. https://doi.org/10.1016/j.compedu.2016.01.007

Pi, Z., Zhang, Y., Zhou, W., Xu, K., Chen, Y., Yang, J., \& Zhao, Q. (2021). Learning by explaining to oneself and a peer enhances learners' theta and alpha oscillations while watching video lectures. British Journal of Educational Technology, 52(2), 659-679. https://doi.org/10.1111/bjet.13048

Pimmer, C., Brühlmann, F., Odetola, T. D., Oluwasola, D. O., Dipeolu, O., \& Ajuwon, A. J. (2019). Facilitating professional mobile learning communities with instant messaging. Computers \& Education, 128, 102-112. https://doi.org/10.1016/j.compedu.2018.09.005

Plötzner, R., Dillenbourg, P., Preier, M., \& Traum, D. (1999). Learning by explaining to oneself and to others. In P. Dillenbourg (Ed.), Collaborative learning: Cognitive and computational approaches (pp. 103-121). Elsevier.

Ray, D., Neugebauer, J., Sassenberg, K., Buder, J., \& Hesse, F. W. (2013). Motivated shortcomings in explanation: The role of comparative self-evaluation and awareness of explanation recipient knowledge. Journal of Experimental Psychology: General, 142, 445-457. https://doi.org/10.1037/a0029 339

Reigeluth, C. M. (1983). Meaningfulness and instruction: Relating what is being learned to what a student knows. Instructional Science, 12, 197-218. https://doi.org/10.1007/BF00051745

Renkl, A. (1995). Learning for later teaching: An exploration of mediational links between teaching expectancy and learning results. Learning and Instruction, 5(1), 21-36. https://doi.org/10.1016/ 0959-4752(94)00015-H 
Renkl, A., \& Eitel, A. (2019). Self-explaining: Learning about principles and their application. In J. Dunlosky \& K. Rawson (Eds.), Cambridge handbook and cognition and education (pp. 528-549). Cambridge University Press.

Rhoads, J. (2019). Distinguishing the effects of verbalizing a skill on performance and learning in novice and skilled populations. [Doctoral dissertation]. https://etd.auburn.edu/handle/10415/6772

Rhoads, J. A., Daou, M., Lohse, K. R., \& Miller, M. W. (2019). The effects of expecting to teach and actually teaching on motor learning. Journal of Motor Learning and Development, 7(1), 84-105. https://doi.org/10.1123/jmld.2017-0052

Richter, J., Lachner, A., Jacob, L., Bilgenroth, F., \& Scheiter, K. (2020). Students' academic self-concept but not prior knowledge moderates effects of virtual experiments on students' learning. Manuscript submitted for publication.

Rittle-Johnson, B., \& Alibali, M. W. (1999). Conceptual and procedural knowledge of mathematics: Does one lead to the other? Journal of Educational Psychology, 91(1), 175-189. https://doi.org/10.1037/ 0022-0663.91.1.175

Rittle-Johnson, B., \& Loehr, A. M. (2017). Eliciting explanations: Constraints on when self-explanation aids learning. Psychonomic Bulletin \& Review, 24(5), 1501-1510. https://doi.org/10.3758/ s13423-016-1079-5

Rittle-Johnson, B., Saylor, M., \& Swygert, K. E. (2008). Learning from explaining: Does it matter if mom is listening? Journal of Experimental Child Psychology, 100(3), 215-224. https://doi.org/10. 1016/j.jecp.2007.10.002

Roediger, H. L., \& Butler, A. C. (2011). The critical role of retrieval practice in long-term retention. Trends in Cognitive Sciences, 15(1), 20-27. https://doi.org/10.1016/j.tics.2010.09.003

Roediger, H. L., \& Karpicke, J. D. (2006). The power of testing memory: Basic research and implications for educational practice. Perspectives on Psychological Science, 1(3), 181-210. https://doi.org/10. $1111 / \mathrm{j} .1745-6916.2006 .00012 . \mathrm{x}$

Roelle, J., \& Nückles, M. (2019). Generative learning versus retrieval practice in learning from text: The cohesion and elaboration of the text matters. Journal of Educational Psychology, 111, 1341-1361. https://doi.org/10.1037/edu0000345

Roelle, J., \& Renkl, A. (2020). Does an option to review instructional explanations enhance examplebased learning? It depends on learners' academic self-concept. Journal of Educational Psychology, 112, 131-147. https://doi.org/10.1037/edu0000365

Rogers, S. L., Fay, N., \& Maybery, M. (2013). Audience design through social interaction during group discussion. PLoS ONE, 8(2), e57211. https://doi.org/10.1371/journal.pone.0057211

Roscoe, R. D., \& Chi, M. T. (2008). Tutor learning: The role of explaining and responding to questions. Instructional Science, 36(4), 321-350. https://doi.org/10.1007/s11251-007-9034-5

Roscoe, R. D., Segedy, J. R., Sulcer, B., Jeong, H., \& Biswas, G. (2013). Shallow strategy development in a teachable agent environment designed to support self-regulated learning. Computers \& Education, 62, 286-297. https://doi.org/10.1016/j.compedu.2012.11.008

Ross, S. M., \& Di Vesta, F. J. (1976). Oral summary as a review strategy for enhancing recall of textual material. Journal of Educational Psychology, 68(6), 689-695. https://doi.org/10.1037/0022-0663. 68.6 .689

Rowland, C. A. (2014). The effect of testing versus restudy on retention: A meta-analytic review of the testing effect. Psychological Bulletin, 140(6), 1432-1463. https://doi.org/10.1037/a0037559

Roy, M., \& Chi, M. T. H. (2005). The Self-explanation principle in multimedia learning. In R. E. Mayer (Ed.), The Cambridge handbook of multimedia learning (p. 271-286). Cambridge University Press. https://doi.org/10.1017/CBO9780511816819.018

Schober, M. F., \& Brennan, S. E. (2003). Processes of interactive spoken discourse: The role of the partner. In A. C. Graesser, M. A. Gernsbacher, \& S. R. Goldman (Eds.), Handbook of discourse processes (pp. 123-164). Lawrence Erlbaum Associates Publishers.

Sharot, T., \& Phelps, E. A. (2004). How arousal modulates memory: Disentangling the effects of attention and retention. Cognitive, Affective \& Behavioral Neuroscience, 4, 294-306. https://doi.org/10. 3758/CABN.4.3.294

Short, J., Williams, E., \& Christie, B. (1976). The social psychology of telecommunications. Wiley.

Silvervarg, A., Wolf, R., Blair, K. P., Haake, M., \& Gulz, A. (2021). How teachable agents influence students' responses to critical constructive feedback. Journal of Research on Technology in Education, 53(1), 67-88. https://doi.org/10.1080/15391523.2020.1784812

Slavin, R. E. (1995). Cooperative learning: Theory, research, and practice (2nd ed.). Allyn \& Bacon. 
Sperling, M. (1996). Revisiting the writing-speaking connection: Challenges for research on writing and writing instruction. Review of Educational Research, 66(1), 53-86. https://doi.org/10.3102/00346 543066001053

Tan, J., Biswas, G., \& Schwartz, D. (2006). Feedback for metacognitive support in learning by teaching environments. In R. Sun \& N. Miyake (Eds.), Proceedings of the 28th Annual Meeting of the Cognitive Science Society (pp. 828-833). Vancouver.

van Brussel, S., Timmermans, M., Verkoeijen, P., \& Paas, F. (2020). Teaching on video as an instructional strategy to reduce confirmation bias. Manuscript submitted for publication.

van der Veen, C., de Mey, L., van Kruistum, C., \& van Oers, B. (2017). The effect of productive classroom talk and metacommunication on young children's oral communicative competence and subject matter knowledge: An intervention study in early childhood education. Learning and Instruction, 48, 14-22. https://doi.org/10.1016/j.learninstruc.2016.06.001

Waldeyer, J., Moning, J., Heitmann, S., Hoogerheide, V., \& Roelle, J. (2020). Does learning by teaching have double-edged effects? Manuscript submitted for publication.

Wang, Y., Lin, L., \& Chen, O. (2021). The benefits of teaching on comprehension, motivation, and perceived difficulty: Empirical evidence of teaching expectancy and the interactivity of teaching. British Journal of Educational Psychology. Advance Online Publication: https://doi.org/10.1111/bjep. 12416

Wäschle, K., Allgaier, A., Lachner, A., Fink, S., \& Nückles, M. (2014). Procrastination and self-efficacy: Tracing vicious and virtuous circles in self-regulated learning. Learning and Instruction, 29, 103114. https://doi.org/10.1016/j.learninstruc.2013.09.005

Wassenburg, S., de Koning, B. B., Koedinger, K. R., \& Paas, F. (2020). Limits of learning by teaching: Explaining to self versus explaining to others. Manuscript submitted for publication.

Webb, N. M., Troper, J. D., \& Fall, R. (1995). Constructive activity and learning in collaborative small groups. Journal of Educational Psychology, 87(3), 406-423. https://doi.org/10.1037/0022-0663. 87.3.406

Weinhuber, M., Lachner, A., Leuders, T., \& Nückles, M. (2019). Mathematics is practice or argumentation: Mindset priming impacts principle- and procedure-orientation of teachers' explanations. Journal of Experimental Psychology: Applied, 25(4), 618-646. https://doi.org/10.1037/xap00 00227

Wittrock, M. C. (1974). Learning as a generative process. Educational Psychologist, 11(2), 87-95. https://doi.org/10.1080/00461527409529129

Wittwer, J., Nückles, M., Landmann, N., \& Renkl, A. (2010). Can tutors be supported in giving effective explanations? Journal of Educational Psychology, 102(1), 74-89. https://doi.org/10.1037/a0016 727

Wolff, F., Helm, F., Zimmermann, F., Nagy, G., \& Möller, J. (2018). On the effects of social, temporal, and dimensional comparisons on academic self-concept. Journal of Educational Psychology, 110(7), 1005-1025. https://doi.org/10.1037/edu0000248

Yerkes, R. M., \& Dodson, J. D. (1908). The relation of strength of stimulus to rapidity of habit formation. Journal of Comparative Neurology and Psychology, 18, 459-482. https://doi.org/10.1002/cne. 920180503

Yoo, Y., \& Alivi, M. (2001). Media and group cohesion: Relative influences on social presence, task participation, and group consensus. MIS Quarterly, 25, 371-390. https://doi.org/10.2307/3250922

Zahn, C., Krauskopf, K., Hesse, F. W., \& Pea, R. (2012). How to improve collaborative learning with video tools in the classroom? Social vs. cognitive guidance for student teams. International Journal of Computer-Supported Collaborative Learning, 7, 259-284.

Zahn, C., Schaeffeler, N., Giel, K. E., Wessel, D., Thiel, A., Zipfel, S., et al. (2014). Video clips for YouTube: Collaborative video creation as an educational concept for knowledge acquisition and attitude change. Education and Information Technologies, 19, 603-621. https://doi.org/10.1007/ s10639-013-9277-5

Publisher's Note Springer Nature remains neutral with regard to jurisdictional claims in published maps and institutional affiliations. 


\section{Authors and Affiliations}

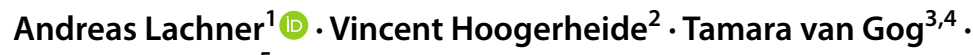 Alexander Renkl ${ }^{5}$}

1 Andreas Lachner, Institute of Education, University of Tübingen, Keplerstraße 17, 72074 Tübingen, Germany

2 Department of Education, Utrecht University, Utrecht, the Netherlands

3 Department of Education, Utrecht University, Utrecht, the Netherlands

4 University of Tübingen, Tübingen, Germany

5 Department of Psychology, University of Freiburg, Freiburg, Germany 